Article

\title{
Interface Shear Performance between Porous Polyurethane Mixture and Asphalt Sublayer
}

\author{
Jun Chen ${ }^{1}(\mathbb{D})$, Cheng Yao ${ }^{1}$, Hao Wang ${ }^{2, *(1)}$, Wei Huang ${ }^{2}$, Xie Ma ${ }^{1}$ and Junyu Qian ${ }^{3}$ \\ 1 College of Civil and Transportation Engineering, Hohai University, Nanjing 210098, China; \\ chen_jun2728@163.com (J.C.); yc520dr9337@163.com (C.Y.); maxiehohai@163.com (X.M.) \\ 2 Department of Civil and Environmental Engineering, Rutgers, The State University of New Jersey, \\ Piscataway, NJ 08854, USA; huang.david@rutgers.edu \\ 3 Department of Civil, Environmental and Ocean Engineering, Steven Institute of Technology, \\ Hoboken, NJ 07030, USA; jqian10@stevens.edu \\ * Correspondence: hwang.cee@rutgers.edu
}

Received: 13 March 2018; Accepted: 13 April 2018; Published: 17 April 2018

\begin{abstract}
This paper aims to study interface shear performance between porous polyurethane mixture (PPM) and asphalt mixture with different adhesive materials. Polyurethane, epoxy resin, and SBS (styrene-butadiene-styrene) modified asphalt were selected as adhesive materials to fabricate composite specimens. The interface shear strength and shear fatigue life of composite specimen was measured using inclined shear test. The research results emphasizes that it is necessary to apply adhesive material to the interface between PPM and asphalt mixture, since the untreated interface shear strength is smaller than the ones between two asphalt mixtures. The interface shear strength is affected by the thickness of adhesive layer, temperature, and freezing-thaw condition. In general, the greatest interface shear strength was achieved by using epoxy resin followed by polyurethane and then SBS modified asphalt at $25^{\circ} \mathrm{C}$ as the adhesive layer thickness is the same. However, the interface shear strengths of composite specimen with three adhesive materials are similar to each other at high and low temperatures $\left(60^{\circ} \mathrm{C}\right.$ and $\left.-18{ }^{\circ} \mathrm{C}\right)$ or after freezing-thaw cycles. On the other hand, the composite specimen with epoxy resin as adhesive material has the longest fatigue life; while the SBS modified asphalt has the least fatigue life at $25^{\circ} \mathrm{C}$. The research findings can help select the appropriate adhesive materials and increase the durability and service life of pavement when PPM is used as road surface layer for safety and noise reduction.
\end{abstract}

Keywords: polyurethane; asphalt mixture; epoxy resin; adhesive layer; shear strength; inclined shear test

\section{Introduction}

The open graded friction course (OGFC) was mainly used as road surface layer placed on dense graded asphalt layer to improve traffic safety at rainy conditions [1,2]. With the high air void content $(18 \%-22 \%)$, OGFC offers safety advantages in terms of high skid resistance and no splash or spray in addition to its benefits in noise reduction and water runoff quality enhancement [3-6]. Despite of the functionality benefits of OGFC, engineering practices have found that the application of OGFC faces three challenges during the service life of pavement, including clogging of air voids $[7,8]$, raveling [9-11], and freezing-induced damage in winter [12,13]. These problems apparently reduce pavement durability and affect the functional benefits of OGFC. Due to the challenges related to OGFC, its use has been limited through the years. A survey conducted in 2016 revealed that 25 states in U.S. do not use OGFC, among which 19 states have used it before but did not continue due to freezing damaged in winter [14]. 
Recently, porous polyurethane mixture (PPM) has been proposed for road surface layer for noise reduction and better durability [15-18]. Although the cost of PPM is higher, PPM has three advantages over OGFC. The first is that it can be mixed at room temperature, which can significantly save heating energy and eliminate the pollution of asphalt smoke during high temperature mixing $[19,20]$. The second is that the PPM performs better to resist particle-related clogging due to its high air void $(30 \%)$, because the pores at the greater porosity are more difficult to be clogged by small particles [18]. Lastly, the polyurethane is hard after curing and can maintain high stiffness during hot days. This makes PPM have better ability to resist deformation-related clogging and produce sufficient bonding with aggregates, which minimize the possibility of raveling [21,22]. The recent work also found that PPM can significantly retard ice-formation time and reduces the adhesive strength with ice, which shows superior anti-icing and deicing performance than OGFC [23].

Since the functional benefit and durability of PPM have been documented, the application of PPM as road surface layer is most beneficial. In this case, the interface bonding between the PPM surface layer and asphalt sublayer is important. However, previous researchers have found that early failure could be caused by the delamination of PPM with its sublayer, especially at tire braking or acceleration conditions [24]. The Japanese Public Works Research Institute (PWRI) found that adhesion of polyurethane mixture was not very durable with dense asphalt mixture but its adhesion with cement concrete was better. Therefore, they developed a semi-flexible layer (porous asphalt with the pores filled with cement) as sublayer of polyurethane mixture to solve the adhesion issue [25]. In the period 2002-2005, full-scale experiments on Japanese highways with eight different types of PPM on three locations all failed within a relative short time after construction (less than one year) owing to raveling, adhesion, and friction problems. The similar interface failure between polyurethane mixture and dense asphalt concrete layer was observed in Sweden only after four months of construction [26]. The reason causing the delamination of PPM could be insufficient bonding between PPM and underlying layer. Therefore, adhesive materials may be needed to improve the interface bonding between PPM and the traditional dense asphalt layer underneath.

Traditionally, asphalt emulsions have been used as tack coat between asphalt layers. It was found that the interface shear strength between asphalt layers was affected by temperature, tack coat type and dosage, surface roughness, and mixture type $[27,28]$. However, few studies have investigated the effectiveness of adhesive material on interface bonding between PPM and asphalt sublayers.

\section{Objectives and Scope}

This study aims to study interface shear performance between porous polyurethane mixture (PPM) and asphalt sublayer with different adhesive materials. Polyurethane, epoxy resin, and SBS (styrene-butadiene-styrene) modified asphalt were selected as adhesive materials to fabricate composite specimens. The interface shear strength of composite specimen was measured using inclined shear test at different temperatures and freezing-thaw conditions. The shear fatigue life of composite specimen with different adhesive materials was also investigated. The test results can be used to select the better performing adhesive material for long-term durability of PPM as surface layer.

\section{Experimental Materials}

Laboratory composite specimens were prepared for shear test with the upper layer and the bottom layer. Three types of upper layer materials were used, including one porous polyurethane mixture with the nominal maximum aggregate size of $9.5 \mathrm{~mm}$ (PPM-10) and two asphalt mixtures with the nominal maximum aggregate size of $13 \mathrm{~mm}$ (AC-13 and OGFC-13). The sublayer material is asphalt mixture with the nominal maximum aggregate size of $19 \mathrm{~mm}$ (AC-20).

Polyurethane was prepared by mixing two components with certain proportion followed by adding catalyst. The mass ratio of catalyst with respect to the two components is determined by the curing time of polyurethane. Based on recommendations from the manufacturer of polyurethane, $2 \%$ catalyst is usually used if the curing time is required within $15 \mathrm{~min}$ after mixing. The two components were isocyanate 
prepolymer (component A) and the mixture of polyether polyol and pentaerythritol (component B). The polyurethane before solidification was transparent yellow liquid under room temperature. Table 1 gives the basic properties of polyurethane. On the other hand, the SBS modified asphalt was obtained by mixing 70\# base asphalt with $4 \%$ SBS polymer at high temperature. The epoxy resin was obtained by manually mixing the resin with curing agent at mass ratio of $1: 1$ at the temperature of $20 \sim 30^{\circ} \mathrm{C}$. It is noted that the mixing should be done unidirectional at constant speed for about one minute in order to prevent the generation of bubbles during mixing or non-uniform mass distribution after mixing.

Table 1. Basic properties of polyurethane binder.

\begin{tabular}{cccc}
\hline Index & Density $\left(\mathrm{g} / \mathrm{cm}^{3}\right)$ & Curing Time $(\mathrm{min})$ & $\mathrm{pH}$ Value \\
\hline Value & 1.003 & $5 \sim 1200$ & 6.7 \\
\hline
\end{tabular}

To prepare porous polyurethane mixture (PPM), basalt aggregates with single grain size of 4.75 9.5 mm were mixed with polyurethane at the mass ratio of $94: 6$ under room temperature. It should be noted that the mass ratio of polyurethane to aggregate particles was determined by the inverse relationship between the dosage of polyurethane and the Cantabro mass loss of specimen measured following AASHTO T108. It was found that the scattering loss rate achieved its minimum value of $6.4 \%$ when the dosage of polyurethane was $6 \%$. The aggregate gradation and polyurethane binder content of PPM-10 can be found in authors' previous work [23].

Three types of asphalt mixture, AC-20, AC-13 and OGFC-13, were prepared by mixing limestone aggregates with 70\# base bitumen. The aggregate gradations, asphalt contents (AC), and air void (AV) contents of different asphalt mixtures are showed in Table 2. The air void contents of PPM and OGFC were determined from the measured bulk specific gravity using paraffin-coated method (AASHTO T275) and the measured theoretical maximum specific gravity (AASHTO T209); while the saturated surface dry method (AASHTO T166) was used for the bulk specific gravity of dense-graded AC specimens.

Table 2. Mix designs for different asphalt mixtures.

\begin{tabular}{|c|c|c|c|c|c|c|c|c|c|c|c|c|c|c|}
\hline \multirow{2}{*}{ Type } & \multicolumn{12}{|c|}{ Mass Percentage (\%) Passing the Below Sieve Size (mm) } & \multirow{2}{*}{$\mathrm{AC}(\%)$} & \multirow{2}{*}{ AV $(\%)$} \\
\hline & 26.5 & 19 & 16 & 13.2 & 9.5 & 4.75 & 2.36 & 1.18 & 0.6 & 0.3 & 0.15 & 0.075 & & \\
\hline AC-20 & 100 & 95.3 & 89.6 & 78.4 & 65.6 & 51 & 39.0 & 28.4 & 16 & 9 & 7.1 & 5.4 & 4.6 & 4.9 \\
\hline AC-13 & 100 & 100 & 100 & 95 & 76.5 & 56.2 & 42.4 & 29 & 20 & 12.7 & 7.9 & 5.4 & 5.0 & 4.2 \\
\hline OGFC-13 & 100 & 100 & 100 & 94.7 & 68.5 & 18.2 & 14.2 & 10.5 & 7.5 & 5.9 & 4.8 & 4 & 5.1 & 20.3 \\
\hline PPM-10 & \multicolumn{12}{|c|}{ Single grain size of $4.75-9.0 \mathrm{~mm}$} & 6.0 & 32.4 \\
\hline
\end{tabular}

Three types of adhesive materials were used at the interface of composite specimen, including polyurethane, epoxy resin, and SBS modified asphalt. It should be noted that the desired thickness of adhesive material applied at the interface was achieved by controlling the mass of adhesive material after knowing the density and coating area. The density of polyurethane, epoxy resin, and SBS modified asphalt is $1.003 \mathrm{~g} / \mathrm{cm}^{3}, 0.971 \mathrm{~g} / \mathrm{cm}^{3}$ and $1.030 \mathrm{~g} / \mathrm{cm}^{3}$, respectively.

\section{Test Method}

\subsection{Specimen Preparation}

A special cylindrical test mold (inner diameter of $101.6 \mathrm{~mm}$ and height of $150 \mathrm{~mm}$ ) made of steel was custom-made for fabricating the composite specimen. According to the Marshall method, the sublayer (AC-20) was initially prepared in the mold after the compaction of 75 times on each side of the specimen, and cured at room temperature for $12 \mathrm{~h}$ without demold. After that, the adhesive material (if needed) was applied on the surface of sublayer and then the upper layer (PPM-10 or AC-13 or OGFC-13) was fabricated after the compaction of 75 times on the top of upper layer, as shown 
in Figure 1. The SBS modified asphalt was hot-applied at the interface at directly. When epoxy resin and polyurethane were used as adhesive materials, the upper layer should be formed within $15 \mathrm{~min}$ to ensure that adhesive materials were not solidified and could penetrate into the upper layer. The composite specimen was then cured for $12 \mathrm{~h}$ at room temperature before testing.

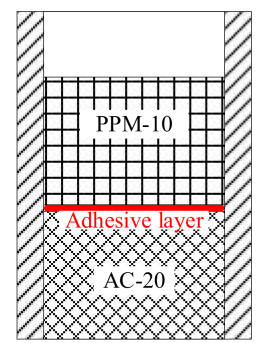

(a)

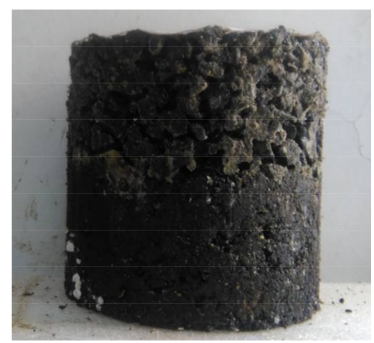

(b)

Figure 1. Preparation of composite specimen: (a) Schematic illustration and (b) picture of real specimen.

\subsection{Inclined Shear Test}

Several testing methods have been used to characterize the interface bonding performance. The modes in these testing methods can be mainly divided into shear, tension, and torsion, in which shearing is the most widely used one. Two types of shear test (direct shear test and inclined shear test) have been used to measure interface shear strength. In the direct shear test, the load direction is parallel to the interface and the confining stress is applied separately [29]. As for the inclined shear test, the load is applied in both parallel and vertical directions with respect to the interface at the same time using an inclined frame [30]. Although the setup of inclined shear test is relatively simple, the ratio of confining pressure to shear stress is defined by the inclined angle and fixed during the test. In the direct shear test, the confining pressure can be applied with varying magnitudes. Further work can be conducted to evaluate interface shear failure using different testing procedures, such as Texas overlay test.

Figure 2 presents the setup of inclined shear test in the laboratory used in this study. The inclination angle between interface axis and horizontal direction was set at $45^{\circ}$ so that the interface was loaded with equivalent shear force and normal force. The load was applied at $5 \mathrm{~mm} / \mathrm{min}$ until the layer interface failed. The shear bonding strength of interface was calculated using Equation (1).

$$
\tau=\frac{F \cdot \sin 45^{\circ}}{S}
$$

where, $\tau$ denotes shear bonding strength of interface; $F$ denotes the maximal vertical load; and $S$ presents the interface contact area between two layers.

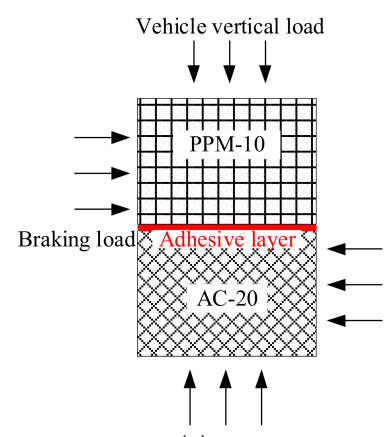

(a)

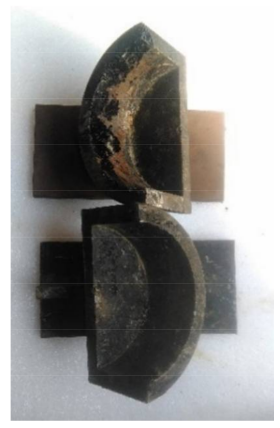

(b)

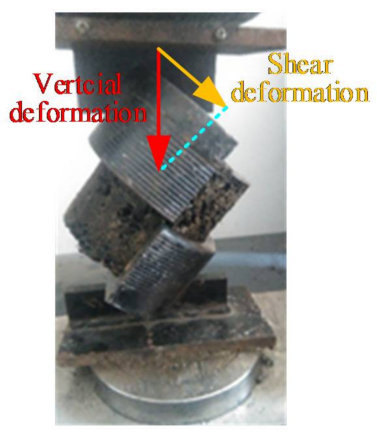

(c)

Figure 2. Illustration of inclined shear test: (a) Force on the specimen; (b) shear clamps; and (c) test setup with specimen. 


\subsection{Test Conditions}

Asphalt pavement is subject to different climate conditions during its service life, including high temperature in summer, freezing-thaw in winter, and water infiltration during rainfall. At rainy days, water can drain vertically through the OGFC and laterally flow to pavement shoulder at wet weather condition due to the internal interconnected voids, which cause less moisture-related distress in OGFC pavement. However, it is documented that the open and interconnected pores in porous asphalt mixtures are easier to be damaged by the volume change due to freezing and thaw as compared to dense-graded asphalt mixtures [13]. Thus, shearing test was applied to composite specimens at different temperatures $\left(-18{ }^{\circ} \mathrm{C}, 25^{\circ} \mathrm{C}\right.$ and $\left.60^{\circ} \mathrm{C}\right)$ and after freezing-thaw cycles. The details of test matrix were presented in Table 3. At each freezing-thaw cycle, the composite specimens were frozen under $-18{ }^{\circ} \mathrm{C}$ for four hours and then immersed in water bath at $15^{\circ} \mathrm{C}$ for four hours. This process was repeated for four times.

Table 3. Test matrix of composite specimens.

\begin{tabular}{cccc}
\hline Test & Freeze-Thaw Cycle & Thickness of Adhesive Layer $(\mathbf{m m})$ & Temperature of Shearing Test $\left({ }^{\circ} \mathbf{C}\right)$ \\
\hline Shear test & No & $0.3,0.5,1.0$ & $-18,25,60$ \\
Shear test & Yes & 0.5 & 25 \\
Shear fatigue test & No & 0.5 & 25 \\
\hline
\end{tabular}

Although the shear strength may indicate the shear resistance of interface for the purpose of ranking, the interface between surface layer and sublayer of asphalt pavement sustains repetitive shear force due to traffic loading. Therefore, stress-controlled inclined shear fatigue test was conducted to evaluate fatigue life of the interface in the composite specimen under repeated loading cycles. The inclined shear test setup shown in Figure 2 was used for fatigue test. A sinusoidal load wave with the frequency of $10 \mathrm{~Hz}$ and peak stress of $0.4 \mathrm{MPa}$ without rest time between cycles was applied at $25^{\circ} \mathrm{C}$ for shear fatigue test. The loading frequency and magnitude was selected based on the typical shear stress magnitude experienced at near-surface under truck loading at highway speeds [24]. The cyclic loading in the fatigue test was applied until that the interface in composite specimen failed. Although currently there is no standard available for shear fatigue test, the similar fatigue test approach has been used in the previous work as the more realistic test to represent the failure process of pavement interface under repeated traffic loading [31,32].

It is noted that uniform shear stress in the interface was assumed in the calculation of shear stress. In the real case, the shear stress may have stress concentrations due to the stiffness difference between asphalt binder and aggregate. This should be investigated with microstructure-based model in future work.

\section{Results and Discussion}

\subsection{Shear Strength of Composite Specimen without Adhesive Material}

Figure 3 illustrates shear stress-deformation curves of three composite specimens without adhesive material at $25{ }^{\circ} \mathrm{C}$. The shear deformation was the projection of total vertical deformation in the direction of interface, as shown in Figure 2c. It can be seen that the interface shear stress first increases to the peak value and then decreases with the increase of shear displacement. The composite specimen PPM-10 + AC-20 has the lowest interface shear strength among three composite specimens without adhesive material. This indicates that the bonding between PPM and asphalt mixture is insufficient compared to the interface between two asphalt layers, which may cause delamination between PPM and its underlying asphalt layer. 


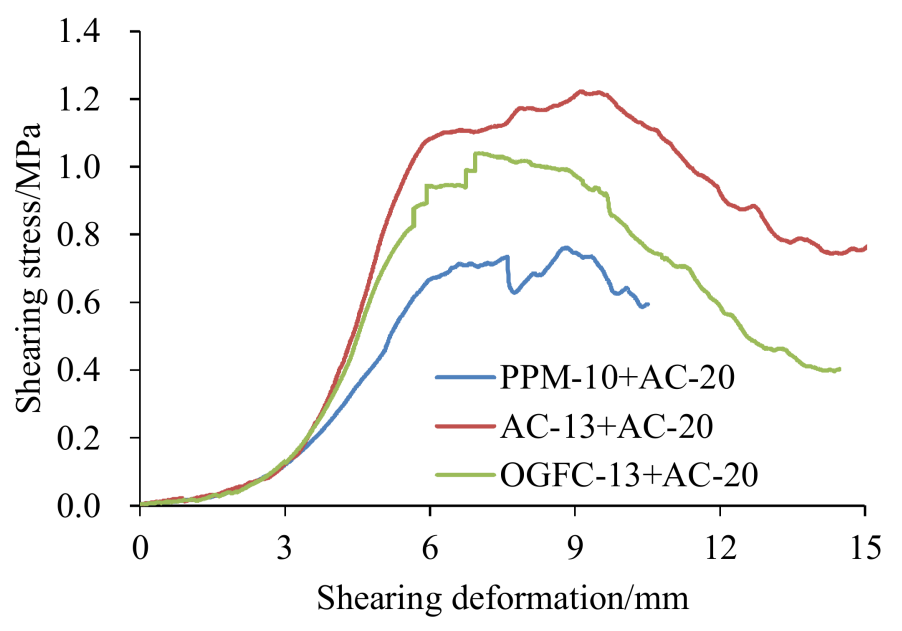

Figure 3. Shear stress-deformation curves of three composite specimens without adhesive materials.

The average shear strengths of three replicates of composite specimens without adhesive material are showed in Figure 4. The standard deviation values were shown as the error bar from the averages in the figure. The results show that the interface shear strength of PPM-10 + AC-20 composite specimen is the lowest at both $25^{\circ} \mathrm{C}$ and $60{ }^{\circ} \mathrm{C}$. This can be caused by two reasons. The first reason is the inter-penetration between the upper and lower layer. For AC-13 + AC-20 and OGFC-13 + AC-20 specimen, the asphalt binder of AC-20 penetrated into the upper layer when AC-13 and AC-20 specimens were compacted at high temperatures, which was different from the case of PPM that was mixed at room temperature. Another reason is that the greater air void of PPM-10 causes the interface contact area smaller than those of the other two composite specimens, resulting in the smaller shear strength. This is similar to the finding reported by previous work, in which it was found that the contact area was an important factor affecting the interface shear strength between OGFC and dense-graded asphalt mixture [32]. The effect of air void on shear strength can be proved by the observation that the interface shear strength between AC-13 and AC-20 is greater than the one between OGFC-13 and AC-20.

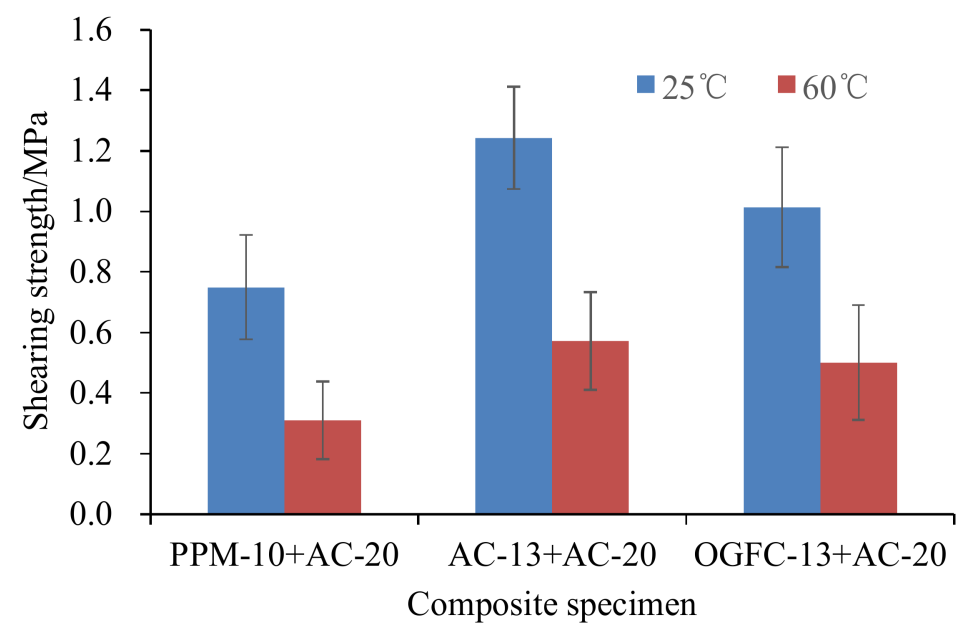

Figure 4. Shear strengths of composite specimen without adhesive materials.

Figure 5 shows the appearance of fractured surfaces after shear testing of composite specimen. It can be noticed that the fractured surface of PPM- 10 + AC-20 composite specimen is smooth, which indicates the pure interfacial failure. However, the fractured surfaces of AC-13 + AC-20 or OGFC-13 + AC-20 composite specimen were found much rougher, which indicated that the failure was 
not pure interfacial sliding due to interlocking of aggregates and inter-penetration of asphalt binder across the interface. The texture profile of interface can be measured using laser sensor or microscopy if more accurate quantification is needed. The insufficient bond between PPM-10 and AC-20 may cause earlier failure of pavement due to slippage cracking or shoveling. Thus, it is necessary to apply adhesive materials to increase the bonding of PPM with the sublayer.

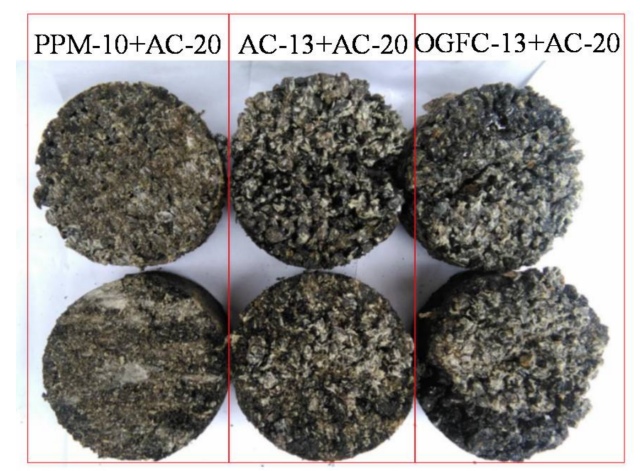

Figure 5. Appearance of fracture surface after shear test for composite specimens without adhesive materials.

\subsection{Shear Strength of Composite Specimen with Adhesive Materials}

Three types of adhesive materials were applied on PPM-10 + AC-20 composite specimens with different adhesive materials and adhesive layer thicknesses at $25^{\circ} \mathrm{C}$. The shear strengths of three replicates of each composite specimen were tested and the results are presented in Figure 6. The standard deviation values were shown as the error bar from the averages in the figure. The mass amounts of adhesive materials used for different thicknesses are shown in Table 4.

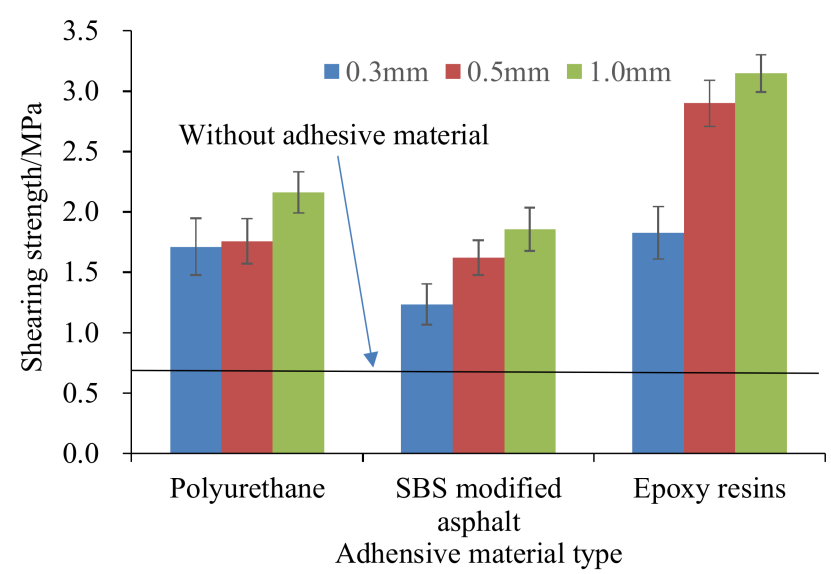

Figure 6. Shear strengths of PPM-10 + AC-20 composite specimen with different adhesive materials and thicknesses at $25^{\circ} \mathrm{C}$.

Table 4. The mass of adhesive material for different thicknesses.

\begin{tabular}{cccc}
\hline Mass of Adhesive Material at Thickness of & $\mathbf{0 . 3} \mathbf{~ m m}$ & $\mathbf{0 . 5} \mathbf{~ m m}$ & $\mathbf{1 . 0} \mathbf{~ m m}$ \\
\hline Polyurethane (g) & 2.4 & 4.1 & 8.1 \\
SBS modified asphalt (g) & 2.5 & 4.2 & 8.3 \\
Epoxy resins (g) & 2.4 & 3.9 & 7.9 \\
\hline
\end{tabular}

According to the results in Figure 6, all the shear strengths of composite specimens are improved as the adhesive layer thickness increases. As polyurethane is used as adhesive material, the interface 
shear strengths with the adhesive layer thickness of $0.3 \mathrm{~mm}$ or $0.5 \mathrm{~mm}$ were very close to each other, but both increased significantly when the adhesive layer thickness increased to $1.0 \mathrm{~mm}$. As SBS modified asphalt was used as adhesive material, the gradual increase of interface shear strength was notable with the increase of adhesive layer thickness, but in general the shear strength was relatively smaller. Meanwhile, the shear strength of epoxy resin increased significantly when the adhesive layer thickness increased from $0.3 \mathrm{~mm}$ to $0.5 \mathrm{~mm}$, but increased slightly as the thickness reached $1 \mathrm{~mm}$. In general, the greatest interface shear strength was achieved by using epoxy resin followed by polyurethane and then SBS modified asphalt as the adhesive layer thickness is the same.

The stress-deformation curves of interface shear test for composite specimens with $0.3 \mathrm{~mm}$ adhesive layer are presented in Figure 7. The results show that the stress-deformation curves are apparently different for three different adhesive materials. The differences were observed in the shear failure pattern and deformation. The interface with epoxy resin had the sudden reduction in shear stress at the maximum shear deformation, while the shear stress of the interfaces with the other two adhesive materials gradually decreased after the peak strength. Since the epoxy resin provides high adhesive strength, the glued aggregates by epoxy resin near the interface can sustain the greater shear stress. As the load increases, aggregate may get broken or be pushed out, which causes the sudden reduction of shear strength. On the other hand, the interfaces with three different adhesive materials had different shear displacements at failure.

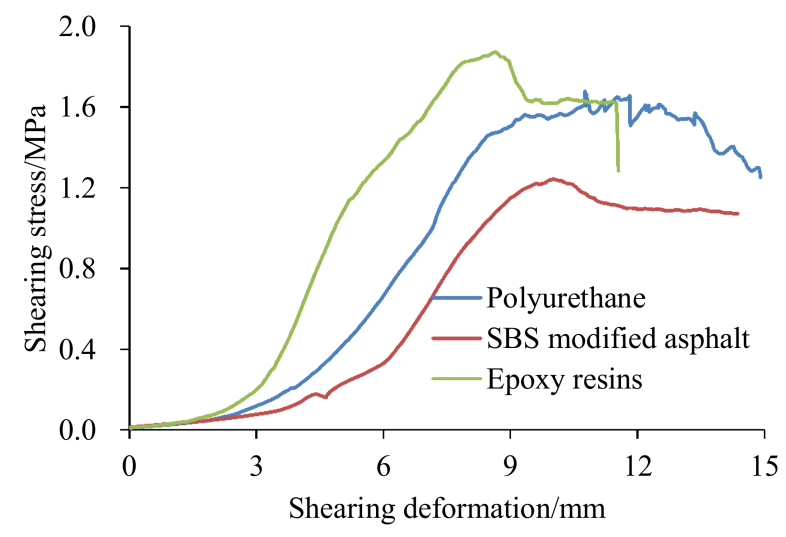

Figure 7. Stress-deformation curves of PPM-10 + AC-20 composite specimens during shear test with $0.3 \mathrm{~mm}$ adhesive layer.

\subsection{Influence of Temperature}

The interface shear strengths of PPM-10 + AC-20 composite specimen with $0.5 \mathrm{~mm}$ adhesive layer at different temperatures are shown in Figure 8. The results show that three adhesive materials offer comparative shear strengths at $-18{ }^{\circ} \mathrm{C}$ and $60{ }^{\circ} \mathrm{C}$. However, compared to SBS modified asphalt or polyurethane, epoxy resin has much greater interface shear strength at $25^{\circ} \mathrm{C}$. It is noted that although the interface shear strength between PPM and asphalt layer decreases significantly as the temperature increases, the shear strengths with adhesive materials are still greater than the ones without adhesive materials at the same temperature.

The stress-deformation curves of interface shear test for composite specimens with $0.5 \mathrm{~mm}$ SBS modified asphalt adhesive layer are presented in Figure 9. The stress-deformation curves are quite different in the peak (shearing strength) for three different temperatures. The shear strength increases greatly with the decrease of temperature. In addition, the failure deformation corresponding to the peak value of shear stress slightly increases as the decrease of temperature. This indicates that the interface shear failure potential of PPM-10 + AC-20 greater in summer.

The appearances of fractured surface after shear testing of PPM-10 + AC-20 composite specimens with $0.5 \mathrm{~mm}$ polyurethane as adhesive layer at different temperatures are shown in Figure 10. When the 
temperature is $-18{ }^{\circ} \mathrm{C}$ or $25^{\circ} \mathrm{C}$, the major bonding failure mode is the separation of layers at the interface. However, when temperature rises to $60^{\circ} \mathrm{C}$, the damage includes not only the interfacial shear failure, but also longitudinal cracks in the upper layer and sublayer. This is due to the strength reduction of mixtures at high temperatures, combined with the stress concentration during the inclined shear test, Figure 11 illustrates the possible stress concentration after the interface slippage occurs, which may cause the cracking of mixtures.

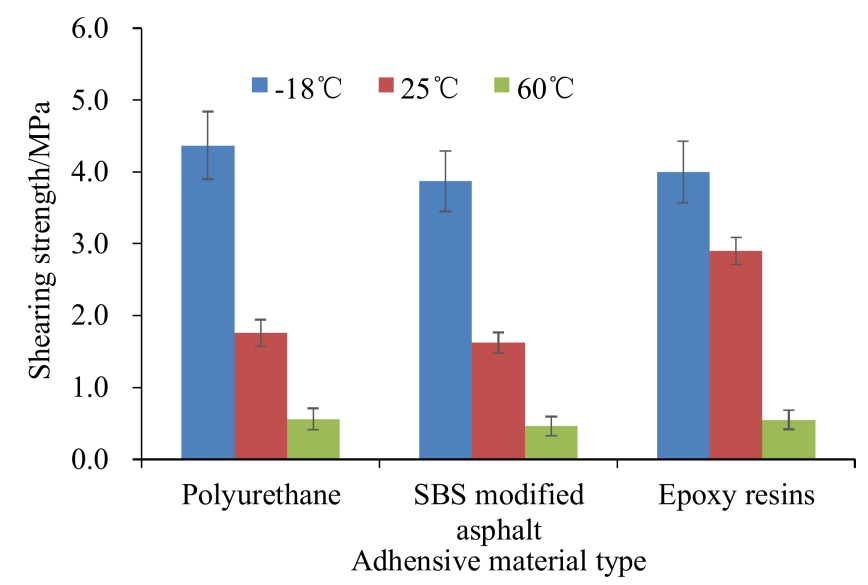

Figure 8. Shear strengths of PPM-10 + AC-20 composite specimen with $0.5 \mathrm{~mm}$ adhesive layer at different temperatures.

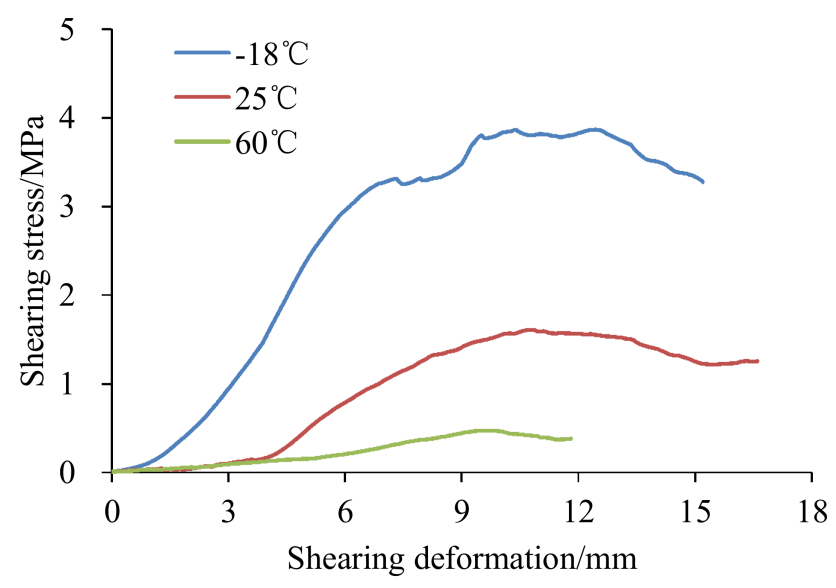

Figure 9. Stress-deformation curves of PPM-10 + AC-20 composite specimens with $0.5 \mathrm{~mm}$ SBS modified asphalt adhesive layer at different temperatures.

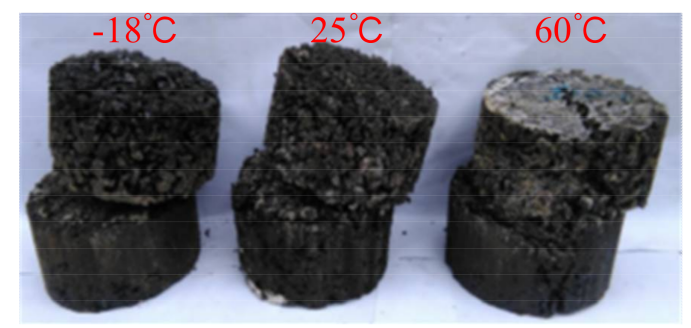

Figure 10. Appearance of PPM-10 + AC-20 composite specimen after shear test. 


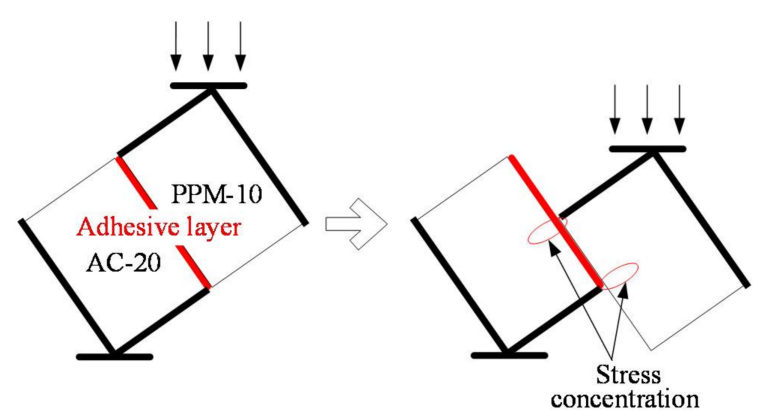

Figure 11. Illustration of stress concentrations during inclined shear test.

\subsection{Influence of Freezing-Thaw Cycles}

After four freezing-thaw cycles, the shear strength of PPM-10 + AC-20 composite specimen with $0.5 \mathrm{~mm}$ adhesive layer was tested at $25^{\circ} \mathrm{C}$. The test results are shown in Figure 12, in which the standard deviation values were shown as the error bar from the averages in the figure. The results show that all the interface shear strengths decrease after freezing-thaw cycles and the results are similar among different adhesive materials. On the other hand, the shear strength of interface with epoxy resin dropped by about $50 \%$ after freezing-thaw cycles, while the shear strength of interface with SBS modified asphalt or polyurethane had much smaller reduction. This indicates that the adhesive ability of SBS modified asphalt or polyurethane is less sensitive to freezing-thaw condition as compared to epoxy resin. Again, all the interface shear strengths after freezing-thaw cycles are greater as compared to the interface of PPM and AC-20 without any adhesive material.

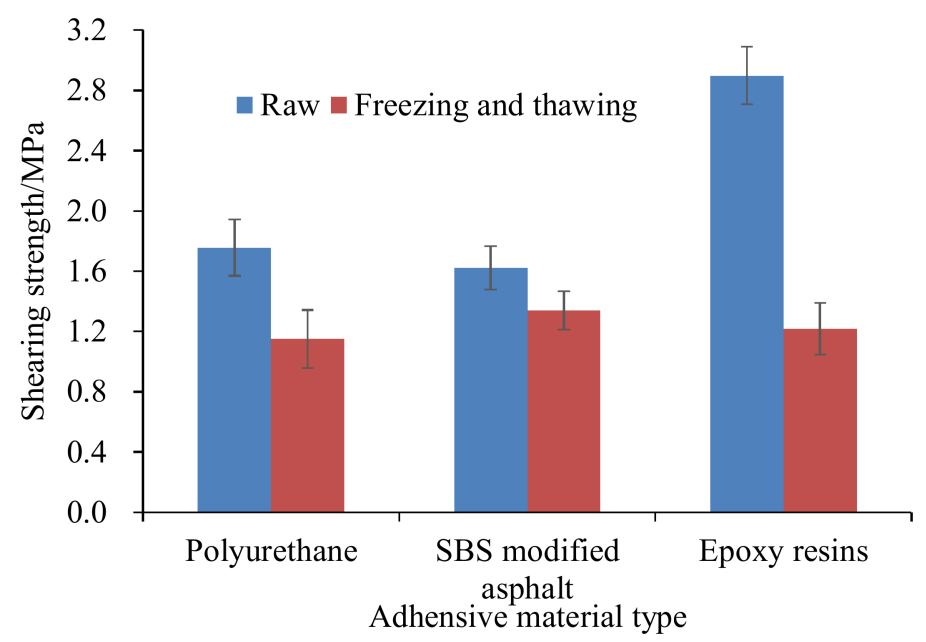

Figure 12. Shear strengths of PPM-10 + AC-20 composite specimen after freezing-thaw cycle with $0.5 \mathrm{~mm}$ adhesive layer.

\subsection{Shear Fatigue Test}

Shear fatigue tests were performed on composite specimens at $25^{\circ} \mathrm{C}$ with the peak shearing stress of $0.4 \mathrm{MPa}$ and the frequency of $10 \mathrm{~Hz}$. Figure 13a shows the change of shear displacement throughout the test. It can be found that the displacement amplitude increases with the increase of number of loading cycles in the first half of the curve. The shear displacement of the interface with epoxy resin is stable in the back half of curve, while the shear displacements of the interfaces with SBS modified asphalt and polyurethane increases rapidly and interface shearing failure occurs at the end of the curve. The number of loading cycles corresponding to the rapid increase of shear displacement was defined as the shear fatigue life. It can be seen that the fatigue life of composite specimen with SBS 
modified asphalt and polyurethane is 1500 and 32,500, respectively; while the epoxy resin provides fatigue life of more than 85,000 cycles for PPM- $10+$ AC-20 composite specimen.

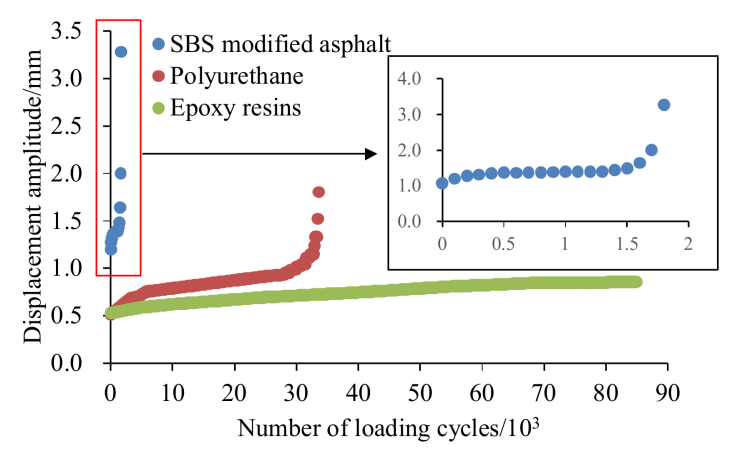

(a)

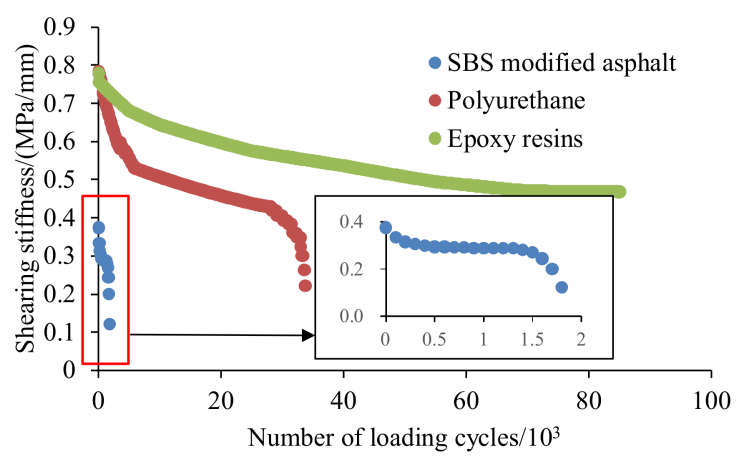

(b)

Figure 13. Response curves of (a) interface displacement vs. number of loading cycles; and (b) shear stiffness vs. number of loading cycles.

Figure 13b shows the interface shear stiffness of composite specimen with three adhesive materials obtained from fatigue test. The interface shear stiffness was calculated using Equation (2).

$$
S=\frac{\tau}{\varepsilon}
$$

where $\tau$ is the shear stress level applied in fatigue test (MPa), which is $0.4 \mathrm{MPa}$ in the paper; and $\varepsilon$ is the shear displacement (mm).

The results show that with the increase of loading cycle, the interface shear stiffness gradually decreases. As the number of loading cycle approaches fatigue life, the shear stiffness decreases rapidly. It was found that the initial stiffness of composite specimen with SBS modified asphalt was $0.37 \mathrm{MPa} / \mathrm{mm}$, while the initial stiffness of composite specimens with polyurethane and epoxy resin reached $0.77 \mathrm{MPa} / \mathrm{mm}$. This indicates that polyurethane and epoxy resin become stiff after curing, which provides the stronger bond than asphalt. Despite of the lowest value during three adhesive materials, the interface shear stiffness of PPM-10 + AC-20 composite specimen with SBS modified asphalt is comparable to that of composite specimen of OGFC-dense asphalt mixture with asphalt emulsion as adhesive material reported in literature [33]. The testing results also proves the feasibility of using the inclined shear fatigue test for measuring shearing fatigue life and shearing stiffness.

\section{Conclusions}

This study investigated shear performance of composite specimen with different adhesive materials using the inclined shear test. The following conclusions can be concluded:

(1) It is necessary to apply adhesive material to the interface between porous polyurethane mixture and asphalt mixture, since the untreated interface shear strength is smaller than the ones between two asphalt mixtures.

(2) The interface shear strength increases as the thickness of adhesive layer increases, although the trends vary depending on the material. In general, the greatest interface shear strength was achieved by using epoxy resin followed by polyurethane and then SBS modified asphalt at $25^{\circ} \mathrm{C}$ as the adhesive layer thickness is the same.

(3) The interface shear strength decreases as the temperature increases or after freezing-thaw cycles. The interface shear strengths of composite specimen with three adhesive materials are similar to each other at high and low temperatures $\left(60^{\circ} \mathrm{C}\right.$ and $\left.-18^{\circ} \mathrm{C}\right)$ or after freezing-thaw cycles, which is different from the trend at $25^{\circ} \mathrm{C}$. 
(4) The composite specimen with epoxy resin as adhesive material has the longest fatigue life; while the SBS modified asphalt has the least fatigue life at $25^{\circ} \mathrm{C}$. Further work will be conducted to evaluate fatigue life of interface at different temperatures and freezing-thaw conditions.

The research findings can help select the appropriate adhesive materials to enhance the interface bonding between porous polyurethane mixture and asphalt layers. Future research should be conducted to investigate the cost-effectiveness of different adhesive materials using field performance data. This will significantly increase the durability and service life of pavement and reduce the life-cycle cost when porous polyurethane mixture is used as road surface layer for safety and noise reduction.

Acknowledgments: The research presented herein was partially sponsored by the National Natural Science Foundation of China (No. 51208178) and the Fundamental Research Funds for the Central Universities (No. 2015B17014).

Author Contributions: Jun Chen and Hao Wang designed the experiment and wrote the paper; Cheng Yao and Xie Ma conducted experiments; Wei Huang and Junyu Qian helped analyzing experimental data.

Conflicts of Interest: The authors declare no conflicts of interest.

\section{References}

1. Nicholls, J.C. Review of UK Porous Asphalt Trial; TRL Rep. 264; Transport Research Laboratory: Wokingham, UK, 1997.

2. Kandhal, P.S. Design, Construction and Maintenance of Open-Graded Aphaltfriction Courses; National Asphalt Pavement Association: Lanham, MD, USA, 2002; Volume 115.

3. Dell'Acqua, G.; de Luca, M.; Lamberti, R. Indirect skid resistance measurementfor porous Asphalt pavement management. Transp. Res. Rec. 2011, 2205, 147-154. [CrossRef]

4. Rungruangvirojn, P.; Kanitpong, K. Measurement of visibility loss due to splash and spray: Porous, SMA and conventional Asphalt pavements. Int. J. Pavement Eng. 2010, 11, 499-510. [CrossRef]

5. Chen, J.; Wang, H.; Zhu, H.Z. Investigation of permeability of open graded asphalt mixture considering effects of anisotropy and two-dimensional flow. Constr. Build. Mater. 2017, 145, 318-325. [CrossRef]

6. Wang, H.; Ding, Y.M.; Liao, G.Y.; Ai, C.F. Modeling and Optimization of Acoustic Absorption for Porous Asphalt Concrete. J. Eng. Mech. 2016, 142, 04016002. [CrossRef]

7. Chen, J.; Zhang, Y.Q.; Li, H.; Gao, Y. Rutting-induced permeability loss of open graded friction course mixtures. J. Test. Eval. 2016, 44, 719-724. [CrossRef]

8. Chen, J.; Li, H.; Huang, X.M.; Wu, J.T. Permeability loss of open graded friction course mixtures due to deformation-related and particle-related clogging: Understanding from a laboratory investigation. J. Mater. Civ. Eng. 2015, 27, 04015023. [CrossRef]

9. Molenaar, A.A.A.; Molenaar, J.M.M. An investigation into the contribution of the bituminous binder to the resistance to raveling of porous Asphalt. In Proceedings of the Papers Submitted for Review at 2nd Eurasphalt and Eurobitume Congress, Barcelona, Spain, 20-22 September 2000; pp. 500-508.

10. Mo, L.T.; Huurman, M.; Wu, S.; Molenaar, A.A.A. Bitumen-stone adhesive zonedamage model for the meso-mechanical mixture design of ravelling resistantporous asphalt concrete. Int. J. Fatigue 2011, 33, 1490-1503. [CrossRef]

11. Mo, L.T.; Huurman, M.; Wu, S.; Molenaar, A.A.A. Mortar fatigue model for mesomechanisticmixture design of ravelling resistant porous asphalt concrete. Mater. Struct. 2014, 47, 947-961. [CrossRef]

12. Xu, H.N.; Guo, W.; Tan, Y.Q. Internal structure evolution of asphalt mixtures during freeze-thaw cycles. Mater. Des. 2015, 86, 436-446. [CrossRef]

13. Yildirim, Y.; Dossey, T.; Fults, K.; Tahmoressi, M.; Trevino, M. Winter Maintenance Issues Associated with New Generation Open-Graded Friction Courses; No. FHWA/TX-08/0-4834-2; Center for Transportation Research, The University of Texas at Austin: Austin, TX, USA, 2007.

14. Hernandez-Saenz, M.A.; Caro, S.; Arámbula-Mercado, E.; Martin, A.E. Mix design, performance and maintenance of Permeable Friction Courses (PFC) in the United States: State of the Art. Constr. Build. Mater. 2016, 111, 358-367. [CrossRef]

15. Amundsen, A.H.; Klaeboe, R. A Nordic Perspective on Noise Reduction at the Source; Report 806/2005; Institute of Transport Economics: Oslo, Norway, 2005. 
16. Goubert, L. Developing a durable and ultra-low noise poroelastic pavement. In Proceedings of the INTER-NOISE and NOISE-CON Congress and Conference, Melbourne, Australia, 16-19 November 2014.

17. Sandberg, U.; Goubert, L. PERSUADE-A European project for exceptional noise reduction by means of poroelastic road surfaces. In Proceedings of the 40th International Congress and Exposition on Noise Control Engineering 2011 (INTER-NOISE 2011), Osaka, Japan, 4-7 September 2011.

18. Yin, J.C.X.J.; Wang, H.; Ding, Y.M. Evaluation of Durability and Functional Performance of Porous Polyurethane Mixture in Porous Pavement. J. Clean. Prod. 2018, 188, 12-19.

19. Sandberg, U.; Goubert, L.; Biligiri, K.P.; Kalman, B. State-of-the-Art Regarding Poroelastic Road Surfaces. Deliverable D8.1 of the PERSUADE Project, VTI and BRRC. 2010. Available online: https:/ / trid.trb.org/ view/918882 (accessed on 16 April 2018).

20. Goubert, L.; Sandberg, U. The PERSUADE project: Developing the concept of poroelastic road surface into a powerful tool for abating traffic noise. In Proceedings of the INTER-NOISE 2010-39th International Congress on Noise Control Engineering 2010, Lisbon, Portugal, 15-16 June 2010.

21. Liao, G.Y.; Wang, H.; Zhu, H.Z.; Sun, P.X.; Chen, H.Q. Shear Bonding Strength between Poro-elastic Road Surface and Sublayer with Different Bonding Agents. J. Mater. Civ. Eng. 2018, 30, 04018017. [CrossRef]

22. Wang, D.; Liu, P.F.; Leng, Z.; Leng, C.; Lu, G.Y.; Bush, M.; Oeser, M. Suitability of poroelastic road surface (PERS) for urban roads in cold regions: Mechanical and functional performance assessment. J. Clean. Prod. 2017, 165, 1340-1350. [CrossRef]

23. Chen, J.; Ma, X.; Wang, H.; Xie, P.Y.; Huang, W. Experimental study on anti-icing and deicing performance of polyurethane concrete as road surface layer. Constr. Build. Mater. 2018, 161, 598-605. [CrossRef]

24. Wang, H.; Al-Qadi, I.L. Evaluation of surface-related pavement damage due to tire braking. Road Mater. Pavement Des. 2010, 11, 101-121. [CrossRef]

25. Kubo, K. Present status of porous elastic rubber surface (PERS) in Japan. In Proceedings of the INTER-NOISE and NOISE-CON Congress and Conference Proceedings 2011, Osaka, Japan, 4-7 September 2011.

26. Ejsmont, J.; Sandberg, U.; Mioduszewski, P. Tyre/road noise reduction by a poroelastic road surface. In Proceedings of the 43rd International Congress on Noise Control Engineering: Improving the World through Noise Control, INTERNOISE 2014, Melbourne, Australia, 16-19 November 2014.

27. Wang, H.; Xu, G.J.; Wang, Z.L.; Bennert, T. Flexible pavement interface bonding: Theoretical analysis and shear strength measurement. J. Test. Eval. 2017, 46, 1-9. [CrossRef]

28. Ai, C.F.; Rahman, A.; Song, J.J.; Gao, X.W.; Lu, Y. Characterization of interface bonding in asphalt pavement layers based on direct shear tests with vertical loading. J. Mater. Civ. Eng. 2017, 29, 04017102. [CrossRef]

29. Canestrari, F.; Ferrott, G.; Partl, M.N.; Santagata, E. Advanced testing and characterization of interlayer shear resistance. Transp. Res. Rec. 2005, 1929, 69-78. [CrossRef]

30. Romanoschi, S.A.; Metcalf, J.B. Characterization of asphalt concrete layer interfaces. Transp. Res. Rec. 2001, 1778, 132-139. [CrossRef]

31. Diakhaté, M.; Millien, A.; Petit, C.; Phelipot-Mardelé, A.; Pouteau, B. Experimental investigation of tack coat fatigue performance: Towards an improved lifetime assessment of pavement structure interfaces. Constr. Build. Mater. 2011, 25, 1123-1133. [CrossRef]

32. Tozzo, C.; Fiore, N.; D'Andrea, A. Dynamic shear tests for the evaluation of the effect of the normal load on the interface fatigue resistance. Constr. Build. Mater. 2014, 61, 200-205. [CrossRef]

33. Song, W.M.; Shu, X.; Huang, B.S.; Woods, M. Influence of interface characteristics on the shear performance between open-graded friction course and underlying layer. J. Mater. Civ. Eng. 2017, 29, 04017077. [CrossRef]

(C) 2018 by the authors. Licensee MDPI, Basel, Switzerland. This article is an open access article distributed under the terms and conditions of the Creative Commons Attribution (CC BY) license (http://creativecommons.org/licenses/by/4.0/). 